\title{
WAGE DIFFERENTIALS BETWEEN NATIVE AND IMMIGRANT WOMEN IN SPAIN: ACCOUNTING FOR DIFFERENCES IN SUPPORT*
}

\author{
Catia Nicodemo** \\ Universitat Autònoma de Barcelona \& IZA \\ Post-doctoral researcher, Departament d'Economia Aplicada \\ Edifici B, Universitat Autònoma de Barcelona, 08193 Bellaterra (SPAIN \\ Tel: $+34+935811528$ \\ Fax: $+34+935812292$ \\ E-mail: catia.nicodemo@uab.cat
}

\section{Raul Ramos}

Grup d'Anàlisi Quantitativa Regional (AQR-IREA), Universitat de Barcelona \& IZA Associate professor, Dept. Econometría, Estadística i Economia Espanyola Avda. Diagonal 690, 08034 Barcelona (SPAIN)

\author{
Tel: +34+934024310 \\ Fax: +34+934021821 \\ E-mail: rramos@ub.edu
}

* The authors would like to thank two anonymous referees for their helpful comments. The usual disclaimer applies.

Catia Nicodemo would like to thank H. Nopo and A. Hoyo Suarez for their suggestions and help and the Jose Castellejo fellowship for its support.

Raul Ramos would like to express his gratitude for the support received from Spain's Ministerio de Ciencia e Innovación (VI Plan Nacional de Investigación Científica, Desarrollo e Innovación Tecnológica 2008-2011) through the action ECO2010-16006 and from the Catalan Government through the project 2010 ARF1 00044.

** Corresponding author. 


\section{WAGE DIFFERENTIALS BETWEEN NATIVE AND IMMIGRANT WOMEN IN SPAIN: ACCOUNTING FOR DIFFERENCES IN SUPPORT}

Purpose: The objective of the study is to quantify the wage gap between native and immigrant women in Spain, taking into account differences in their characteristics and the need to control for common support. If immigrant women are segregated in occupations with few native women, it is important to take this into account to analyse wage differentials between both collectives.

Methodology: We use microdata from the Continuous Sample of Working Histories (Muestra Continua de Vidas Laborales) on wages and other personal characteristics such as gender, country of origin, and age to apply the matching procedure and the decomposition of the wage gap along the lines of Ñopo (2008) for the analysis of wage differentials between native and immigrant women. The advantage of this procedure is that we can simultaneously estimate the common support and the mean counterfactual wage for the women on the common support (i.e., comparing native and immigrant women with similar observable characteristics). In addition, we can describe differences not only at the mean but also along the entire wage distribution.

Findings: The results obtained indicate that, on average, immigrant women earn less than native women in the Spanish labour market. This wage gap is bigger when we consider immigrant women from developing countries, but our main finding is that an important part of this wage gap is related to differences in common support (i.e., immigrant women are segregated in certain jobs with low wages different from those occupied by native women). If the need to control for common support is neglected, estimates of the wage gap will be biased.

Originality: Studying the case of Spain is particularly interesting because it is a country with abundant and recent immigration. Immigrant women account for more than half of the total immigrants in Spain, and unlike other host countries, they come from a highly varied range of countries, with origins as diverse as Latin America, the Maghreb and Eastern Europe. To our knowledge, no other study has explicitly focused on the analysis of the wage differential of immigrant women in the Spanish labour market by taking into account the need to control for common support. Moreover, published papers illustrating the potentiality of Ñopo's (2008) methodology are also very scarce.

Keywords: Common support, quantile regression, immigration, counterfactual decomposition

JEL Classification: J16, J31, C2, C3

\section{Research paper}

Word count: 7439 


\section{WAGE DIFFERENTIALS BETWEEN NATIVE AND IMMIGRANT WOMEN IN SPAIN: ACCOUNTING FOR DIFFERENCES IN SUPPORT}

\section{Introduction and motivation}

Studying immigration in the Spanish labour market is a matter of great interest because Spain has become a country with significant migration flows in the international context in a relatively short time (OECD, 2011). Spain ranks third among OECD countries after the United States and Germany in absolute numbers of foreign population, and it stands fourth after Luxembourg (43.8\%), Switzerland (21.7\%) and Estonia (16.4\%) in percentage of foreigners in the population (12.4\%). Those figures put Spain ahead of all other members of the European Union. The growth of the stock of immigrants was particularly intense between 1995 and 2007 , rising steeply from 542,300 foreigners (1.4\% of the population) in 1995 to $5,268,800(11.7 \%)$ in 2007 . The economic crisis has changed the dynamics of migration flows, and in 2009, the number of immigrants was 5,708,940, reflecting a strong slowdown in new entries and a very low incidence of return migration. Taking these figures into account, extensive research is needed to devise immigration strategies and policies to guarantee economic well-being and social stability. In this context, the analysis of wage differentials is relevant because wages are the most important source of immigrant income. Furthermore, because of the recent nature of the migratory phenomenon in Spain and the limitations of the available datasets, academic research on the topic is scarce. Simón et al. (2008), Izquierdo et al. (2009) and Antón et al. (2010a) have analysed wage differences among native-born workers and immigrants in Spain, but the role of gender was not central to their research.

The analysis of gender differences is also relevant for the Spanish case for two reasons: first, as previously mentioned, the literature on wage discrimination with immigrant women is practically inexistent and, second, women account more than half of recent immigration to Spain coming from a wide variety of countries in terms of levels of development, language and cultural proximity to Spaniards but also in terms of the types of jobs they have (AmuedoDorantes and de la Rica, 2011). In fact, although the number of new immigrants has been decreasing in the last years from nearly 700,000 in 2005 to fewer than 25,000 in 2010, the 
number of women migrating to Spain for work was more than 200,000 until 2010, when it fell to 75,000, a value significantly higher than that observed for men. This difference is a result of the increasing demand for workers to do jobs with low pay and low prestige in sectors (such as domestic service) where most of the workforce is female.

Taking these figures into account, this paper reviews the position of immigrant women, drawing on recent research on the labour market situation of female immigrants in Spain. Our objective is to understand the disadvantages of female immigrant workers relative to native female workers as well as between and within them. From a methodological point of view, we decompose the wage gap using a matching procedure along the lines of Nopo (2008). The advantage of this procedure is that we can simultaneously estimate the common support and the mean counterfactual wage for the women on the common support (i.e., a similar group of natives and immigrants). In addition, the decomposition of the wage gap explicitly accounts for differences in the support for the distributions of characteristics. Finally, this matching method provides useful information about the unexplained wage gap not only at the mean but also along the distribution of this gap over the entire wage distribution. This is novel in the related literature and in terms of the few applications illustrating the potentiality of Nopo's (2008) methodological proposal [1].

This study allows us to understand which group of immigrants is more vulnerable to discrimination or segregation in the labour market because not all immigrants have the same results. For example, some groups are more disadvantaged because of cultural or language differences. It is important to identify these groups to develop new policies to prevent these disadvantages.

The remainder of the paper is structured in five sections. First, we summarise previous research on the topic; second, the applied methodology is described; third, we provide details on the data sources used for the research; fourth, we present the obtained results for the analysis of wage differentials for different groups of immigrant women; and finally, the paper concludes with a summary of the main results and the policy implications of our analysis. 


\section{Literature review}

The relative disadvantage of immigrants in the labour market of the host country has been extensively analysed in recent studies. These studies have put special attention on immigrant wages relative to those of native-born workers, and their findings can be summarised as follows: first, immigrants typically face a significant wage gap relative to native workers, and second, the gap tends to diminish the longer immigrants remain in the host country [2].

Similarly, significant wage differences between men and women have also been detected in several studies [3]. However, the number of studies considering the particular case of immigrant women is relatively scarce.

In fact, most studies analysing the situation of immigrant women in the labour market have focused on whether they suffer from double discrimination. In summary, these studies conclude that some groups of immigrant women experience a double wage penalisation: first, they suffer discrimination towards native people, and second, they have more disadvantages in the labour market than immigrant men.

A study by Long (1980) was the first to analyse the specific situation of immigrant women in the United States. His results are quite different from those obtained by Chiswick (1978) for the case of immigrant men: an initial negative wage gap for immigrant that reduces with years of residence in the host country. In particular, he found that the wages of immigrant women were higher than those of native women even after controlling for personal characteristics.

Following a similar approach, Beach and Worswick (1993) examined the situation of immigrant women in the Canadian labour market using data from the 1973 Job Mobility Survey. Their results show that, although the wages of immigrant women were not significantly different from those of native women, highly educated immigrant women earn less than their native counterparts.

Taking the evidence found by Beach and Worswick (1993) for educated immigrant women as a starting point, other authors have investigated whether there is a double-negative effect on the wages of immigrant women stemming from both gender and foreign country of origin [4]. 
This double disadvantage could arise from an environment of unequal opportunity in the labour market, which negatively affects both women and migrants. According to this hypothesis, women migrants will have more difficulties integrating into the labour market than both native-born women and migrant men. According to Rubin et al. (2008, p. 45), "Migrant women, in a sense, face a double battle; first to migrate and integrate as foreignborn people in their host country, and then to overcome the gender bias in the labour market."

One of the first studies to adopt this perspective was conducted by Shamsuddin (1998). This author applied a decomposition approach to explore the possible presence of a doublenegative effect on the wages of immigrant women using more recent data for Canada than the data from Beach and Worswick (1993). Shamsuddin concluded that all foreign-born women suffer from double-negative discrimination and that, in fact, gender discrimination seems to be more prevalent than discrimination by birthplace. However, based on a Danish panel of register data, Nielsen et al. (2000) also found that all women were affected by substantial gender discrimination in wages, but only Pakistani women experienced a double-negative effect. In contrast, Hayfron (2002), using data for Norway, found evidence of a doublenegative effect on the earnings of female immigrants.

Adserà and Chiswick (2007) used the 1994-2000 waves of the European Community Household Panel to compare the earnings of immigrants to those of native workers in 15 European countries. These authors found a significant negative effect of foreign birth on individual earnings at the time of arrival in the destination country compared to the earnings of native-born workers of approximately $40 \%$. These differences varied across origins and destinations and by gender, but the study did not find clear evidence of double discrimination.

Rehbuhn (2009) analysed gender differences in earnings among the foreign-born in Israel and how these differences vary by country of origin. The results from the Israel 1995 population census indicate that, all else being equal, immigrants, including immigrant women, out-earn native-born men. The effect of tenure, by single year, shows that immigrant men and immigrant women follow very similar trajectories, but immigrant women achieve similarity to native-born men much sooner. A detailed analysis reveals important heterogeneity by country of birth. All of the immigrant women who out-earned native men and native women originated in America or Europe. By contrast, all immigrant women who are at a disadvantage relative to native-born men are from Asia or Africa. The most common pattern, in which 
immigrant women earn as much as native-born men but out-earn native-born women, is related to three factors: absorption climate, immigration motivation, and socio-cultural norms. Rehbuhn's results also highlighted the relevance of considering heterogeneity when analysing double discrimination towards immigrant women.

Le and Miller (2010) used 1990 and 2000 US Census data to analyse wage differentials for three groups of workers: the native born, immigrants from English-speaking countries and immigrants from non-English-speaking countries. Quantile regression estimates revealed that females have lower rates of pay across the entire wage scale, but only immigrant women from non-English-speaking countries experience a double disadvantage effect.

The only study, to our knowledge, that has explicitly focused on the situation of immigrant women in the Spanish labour market was conducted by Antón et al. (2010b). They analysed the differential access to employment and the earnings penalty faced by immigrant women when compared to all natives using data from the Labour Force Survey and the Wage Structure Survey for 2006. Their results support the hypothesis of double discrimination, and they found that the earnings gap between female natives and female migrants, which amounts to approximately $20 \%$, nearly disappears on average when controlling for observable characteristics. However, these results do not take into account the relevance of considering "differences in support. This aspect is relevant because immigrants can have very different observable characteristics than natives, and when this is the case, there will be a problem of comparability between the two groups. Because migrant females tend to concentrate in certain occupations in which native females and native men do not work, traditional wage decomposition will fail to recognise these differences in the support and will result in a biased picture of the magnitude of the wage gap and its explanatory variables.

\section{Methodology}

Various decomposition methods have been proposed to account for the explained and unexplained components of the wage gap. The most popular method is based on a parametric approach. Following Blinder (1973) and Oaxaca (1973) (hereafter BO), separate wage functions as estimated for males and females take into consideration personal characteristics (see Mincer, 1974). The difference in average wages between males $(M)$ and females $(F)$ can 
be decomposed into differences in personal characteristics (endowment effect) and differences in returns (remuneration effect):

$$
\underbrace{\Delta \ln W}_{\text {Raw wage gap }}=\underbrace{\beta^{M} \cdot\left(\bar{X}^{M}-\bar{X}^{F}\right)}_{\text {Endowment }}+\underbrace{\left(\bar{\beta}^{M}-\bar{\beta}^{F}\right) \cdot \bar{X}^{M}}_{\text {Remuneration }}
$$

Junh et al. (1993) (hereafter JMP) extend the method proposed by BO, attempting to account for the unobserved heterogeneity. However, both methods, BO and JMP, estimate the average of unexplained difference in pay but not its distribution. Various solutions have been proposed in the literature. Buchinsky (1994) overcomes this limitation by estimating the quantile earning equations. DiNardo et al. (1996) used a semi-parametric model to explore the distribution of unexplained differences, whereas Donald et al. (2000) suggested a different semi-parametric approach. A different approach was proposed by Barsky et al. (2001), who suggested including only one explanatory variable (income) to avoid the problem of dimensionality in non-parametric estimation. They recognised for the first time the importance of "differences in support and restricted the comparison to the common support. This aspect is relevant because there are combinations of individual characteristics for which it is possible to find individuals from one of the groups but not from the other. This problem of comparability is accentuated when job characteristics are included in the explanation of the wage gap. Because migrant females tend to concentrate in certain occupations that do not engage native females or men, the traditional BO decomposition will fail to recognise these differences in the support. Moreover, this decomposition is informative only about the average unexplained difference in wages and not about the distribution of these unexplained differences.

Following this idea, Nopo (2008) adapted a tool of the programme evaluation literature, matching, to fix the problem. The main advantage of this procedure is that it provides additional information about the distribution of the differences in wages that remain unexplained by the characteristics of the individuals after decomposition without requiring any estimation of earnings equations and, hence, no validity-out-of-the-support assumptions [5]. In this study, we follow the Nopo (2008) method and propose to consider immigration differences in support. In the analysed sample, there are some combinations of characteristics that are typical for natives but not for immigrants and vice versa (schooling level, language, culture). We propose to decompose the wage gap between natives and immigrant women, 
taking into account the differences in the distributions of individual characteristics and, in particular, immigrants' differences in support. Specifically, the proposed approach considers the country of birth as a treatment and uses a matching procedure to select sub-samples of natives and immigrant women such that there are no differences in observable characteristics between the matched groups.

To illustrate the methodology that we use to decompose the wage gap between immigrant women and native women, suppose that there are two groups, natives $(N)$ and immigrants $(M)$, and that we decompose wage differences between the two groups by applying the matching procedure in the following way:

First, as shown in (2) and (3), we calculate the expected value of earnings conditional on the characteristics of the two groups:

$$
\begin{aligned}
E[Y \mid L] & =\int g^{N}(x) d F^{N}(x) \\
E[Y \mid A] & =\int g^{M}(x) d F^{M}(x)
\end{aligned}
$$

Next, we decompose the difference in terms of observed wages and the respective counterfactuals, as shown in (4) and (5):

$$
\begin{gathered}
\Delta=\int_{S^{N}} g^{N}(x) d F^{N}(x)+\int_{S^{M}} g^{N}(x) d F^{N}(x) \\
\Delta=\left\lfloor\int_{\bar{S}^{M} \cap S^{N}} g^{N}(x) d F^{N}(x)+\int_{S^{N} \cap S^{M}} g^{N}(x) d F^{N}(x)\right]- \\
{\left[\int_{S^{N} \cap S^{M}} g^{M}(x) d F^{M}(x)+\int_{S^{M} \cap \bar{S}^{N}} g^{M}(x) d F^{M}(x)\right]}
\end{gathered}
$$

The expression in (5) can be understood as four additive components of the total wage difference (see Ñopo, 2008, for details):

$$
\Delta=\Delta_{M}+\Delta_{N}+\Delta_{X}+\Delta_{0}
$$

where: 
- $\Delta_{\mathrm{N}}$ is the part of the wage gap that can be explained by differences between two groups of native women, those who have characteristics that can be matched to immigrants' characteristics and those who do not.

- $\Delta_{\mathrm{M}}$ is the part of the wage gap that can be explained by differences between two groups of immigrant women, those who have characteristics that can be matched to native characteristics and those who do not.

- $\Delta_{\mathrm{X}}$ is the part of the wage gap that can be explained by differences in the distribution of individual characteristics of native and immigrant women over common support.

- $\quad \Delta_{0}$ is the unexplained part in BO: $\left(\beta^{N}-\beta^{M}\right) \cdot X^{M}$. This difference is attributed to the unobservable characteristics and/or to discrimination between native and immigrant women.

To calculate these four terms, we consider the following variables that are perfectible matching between the considered groups to identify individuals with characteristics similar to those of our treatment group. In particular, we use four different sets of characteristics $x$ to check the relative importance of each of them but also as a robustness check of our results. When analysing the gender wage gap using data for urban Peru for 2000, Nopo (2008) considers various specifications, including age, age squared, years of education and years of experience in the occupation. In our case, we have taken a similar approach, taking into account that the starting point in both cases is a Mincer equation when individual wages are explained mainly by human capital characteristics; thus, our set of characteristics is similar, although we have included some additional controls such as the number of children and some job characteristics, including occupational and firm segregation (firm segregation is among the most relevant factors to explain the gender wage gap for the Spanish case, according to previous studies such as that by Simón et al., 2008.) The first group of variables consists of only age and schooling level; next, we include age and occupation; the third set of variables includes age, schooling level and number of children; and, finally, we include age, schooling level, number of children, activity sector, occupation and firm size. Of course, when the 
number of characteristics is increased, the probability of finding a perfect matching decreases. The applied matching procedure was performed as follows: first, we select one immigrant woman from the sample (without replacement); second, we select all native women who have the same characteristics $x$ as the immigrant woman selected previously; third, we construct a synthetic sample with all individuals who enter in this match; finally, we calculate their average wage and match it with the original immigrant who was used to create the sample of matched natives. This algorithm is repeated for each individual in the immigrant women sample.

\section{Data sources}

To design our study, we use the Continuous Sample of Working Histories (Muestra Continua de Vidas Laborales; hereafter MCVL) for 2008. These data represent more than 1 million people in the Social Security System in Spain. The MCVL started in 2004, and workers are a random sample of those affiliated with the Social Security System in the year when the survey was conducted and reproduces the labour history of the affiliated people starting with their first job.

The MCVL is an appropriate database to use to study the labour market in Spain and, in fact, has several advantages when compared to the Labour Force Survey (LFS) or the Wage Structure Survey (WSS) because it provides more exhaustive information on the labour trajectories of workers. The data set gives information of all of the historical relationships of any individual with the Social Security System (in terms of work and unemployment benefits). We also have information regarding the type of contract, sector of activity, qualification and earnings that an individual must pay each month to the Social Security System, date when entering or leaving the job market, part-time or full-time status and firm size. Moreover, the database contains information on gender, nationality, residence, date of birth and level of education.

To analyse the wage gap between immigrant and native workers, we use the daily wage, calculated as the ratio of annual earnings to days worked during the year 2008. We eliminated observations when the daily earnings were below the minimum base or exceeded the maximum base (the Social Security System set the minimum base in 2008 at approximately 500 euros per month and the maximum at 2800 euros) to avoid the problem of censured data. 
We have also excluded from the analysis those individuals working for less than 30 days and those having more than one job.

\section{Empirical results}

\subsection{Descriptive analysis}

In figure 1, we report the kernel density of the daily wage between native and immigrants in 2008, distinguishing between men and women. As can be seen, there are clear differences among the four considered groups. Native men have the highest concentration in higher wages, followed by native women, whereas immigrants are concentrated in low-paying occupations. The situation of immigrant women is clearly the worst, confirming the "double disadvantage" hypothesis for the Spanish case.

\section{FIGURE 1}

If we examine wage differentials between women according to their country of birth, the distribution of daily wage between native and immigrant women is shown in figure 2 , whereas figures 3 and 4 show the situation of immigrant women from developed and developing countries [6] when compared with native women, respectively. It is clear that the gap is bigger for women from developing countries and smaller, and even negative, for women from developed countries.

\section{FIGURES 2, 3 AND 4}

Table 1 complements the previous descriptive analysis. In particular, we report the daily absolute wage gap and the percentage of foreign women relative to native women (i.e., the percentual wage difference between native and immigrants in terms of native: $\left.\left(\mathrm{W}^{\mathrm{N}}-\mathrm{W}^{\mathrm{M}}\right) / \mathrm{W}^{\mathrm{N}}\right)$ and descriptive statistics for observed characteristics. As this table shows, the daily wage for native women is $15.52 \%$ higher than the daily wage for immigrant women, and the gap is significantly lower for immigrant women from developed countries $(2.51 \%)$ and higher for immigrant women from developing countries (17.07\%). There are also significant differences in terms of observable characteristics between these three groups. Compared to native women or immigrant women from developed countries, immigrant women from developing countries 
are more concentrated in lower educational levels and lower qualified occupations, in some services sectors such as hotels and restaurants and in smaller firms. For all immigrant women, experience is significantly lower, and in fact, this variable can also be treated as a proxy for the number of years of residence in Spain. As mentioned in the methodology section, these observable differences should be taken into account to establish a group of native female workers with characteristics similar to those of immigrant female workers to properly decompose the wage gap. We do this in the next section.

\section{TABLE 1}

\subsection{Wage gap decomposition results}

If we examine the results in table 1 related to the wage gap decomposition among natives and immigrant women in 2008 in Spain, we find that native women earn on average 3.7\% more than immigrants, and in particular, the wage gap $(\Delta)$ is $4.08 \%$ for developing countries and only $0.78 \%$ for developed countries, confirming that immigrants in developed countries are fairly well assimilated and more similar to native people. As mentioned in the methodology section, we use different sets of variables to calculate the wage gap; in particular, we define four sets of variables:

- Set 1: Age, schooling

- Set 2: Age, occupation [7]

- Set 3: Age, occupation, number of children

- Set 4: Age, occupation, number of children, experience

- Set 5: Age, schooling, number of children, experience, sector, occupation, firm size

The inclusion of many explanatory variables may reduce the likelihood of obtaining an adequate number of matched observations. Here, we follow the general literature related to the analysis of the labour market for females. We know that most variables affecting wages are directly related to the labour market, such as experience, occupation, level of education, qualification and number of dependent children (see Becker, 1964, for details). 
In figures 5, 6 and 7, we show the results of the decomposition of the wage gap after matching the different sets of characteristics for total immigrants and for immigrants from developed and developing countries versus native females. The components $\Delta_{\mathbf{0}}$ and $\boldsymbol{\Delta}_{\mathbf{x}}$ primarily explain the wage gap. As we can see, when controlled for a reduced number of variables (sets 1, 2 and 3 ), the most important component of the wage gap is the unexplained part $\left(\boldsymbol{\Delta}_{\mathbf{0}}\right)$ in all comparisons. The difference in individuals' characteristics on the common support $\left(\boldsymbol{\Delta}_{\mathbf{x}}\right)$ also represents an important part but only between immigrants who come from developing countries. However, for immigrants coming from developed countries, the effect is negative, which implies that women from developed countries have the same or better characteristics than native women. This implies that they should receive even lower wages than those observed [8]. When we include more characteristics (sets 3 and 4), we can observe that, as expected, the unexplained part $\left(\boldsymbol{\Delta}_{\mathbf{0}}\right)$ decreases and becomes negative. This cannot be interpreted as a "reverse" discrimination effect, but it is probably related to a "selection at entry effect" (i.e., segregation). Moreover, as we include more variables in the matching, we can see how the other two components $\left(\Delta_{\mathbf{N}}\right.$ and $\left.\Delta_{\mathbf{M}}\right)$ increase the explanatory power of the wage gap attributable to differences in support. Both components are positive, and in particular, $\Delta_{\mathbf{N}}$ explains a large part of the wage gap. This is an interesting result because it shows that the wage gap between natives and immigrants is related to unobservable characteristics and to differences in characteristics that are better rewarded in the labour market for natives than for immigrants.

\section{FIGURES 5, 6 AND 7}

Next, we focus on the analysis of the quantile distribution of unexplained differences in pay $\left(\Delta_{0}\right)$. In table 2 , we present the values of $\Delta_{0}$ for the three groups of considered workers: total immigrants, immigrants from developing countries and immigrants from developed countries. We also present the percentages of immigrants and native women that remain unmatched when we use the sample of total immigrants for the different sets of combinations of characteristics. As we can see from this table, as we increase the number of controls, it becomes much more difficult to establish an appropriate group of native and immigrant women for the comparison. In fact, these difficulties in carrying out a good matching are a clear sign of the magnitude of the bias incurred if differences in support are not taken into account. 


\section{TABLE 2}

Finally, figures 8, 9 and 10 show the unexplained wage gap $\left(\boldsymbol{\Delta}_{\mathbf{0}}\right)$ by quantile. The left panel of these figures represents the wage gap that remains after matching in absolute terms. As we can see from these figures, for quantiles below the $60^{\text {th }}$, wage differences between native and immigrants are relatively small, but they clearly increase at the top of the distribution. It appears that, at the bottom of distribution, there is a type of positive discrimination, in the sense that immigrants with low skills have better returns than native workers with similar skills. However, at the top of the distribution, the unexplained wage gap is clearly positive, although this effect is mitigated when we consider immigrants from developed countries (in particular, for sets 4 and 5 , the unexplained wage gap is very small). In the right panel of the figures, we present the relative unexplained wage gap, which is equal to the wage differences between natives and immigrants in relation to the wages of native workers $\left.\left(\mathrm{W}^{\mathrm{N}}-\mathrm{W}^{\mathrm{M}}\right) / \mathrm{W}^{\mathrm{N}}\right)$. As we can see, the relative wage gap decreases because the wage of natives is larger than the wage of immigrants, making the odds decrease, although the difference still remains larger at the top of the wage gap distribution.

FIGURES 8, 9 AND 10

\section{Conclusions}

Our objective was to analyse wage differentials between native and immigrant women using a non-parametric technique to decompose the wage gap, taking into account not only the explained and unexplained components but also considering the problem of differences in support (i.e., not all immigrants are comparable to all natives). If differences in the common support are not considered, the unexplained wage gap will be overestimated. After taking this into account, our results showed that immigrant women earn less than natives, and this wage gap is related to the unexplained wage component and to differences in common support. In particular, most of the characteristics that native women have and immigrants do not have are better rewarded in the labour market.

The considered method also has an advantage in the estimation of female wage decomposition because it is based on the matching between observable individuals and, as a result, does not need to account for selection bias as in other decomposition methods such as 
BO. Moreover, using matching techniques, it is also possible to observe the unexplained wage gap along the whole distribution. This is not possible with simple regression methods that are based only on the average. Exploring the unexplained wage gap along the whole distribution, we have also found that the wage differences are larger at the top quantiles, whereas at the bottom distributions, the unexplained wage gap does not contribute much to explaining the difference between native and immigrant women. We have also observed that the wage gap is larger for immigrants from developing countries and is quite small or nonexistent for those immigrants coming from developed countries. We discovered that immigrants who come from developing countries are subjected to some type of segregation, and they are unable to break out of this dependence trap. Considering these results, we can conclude that, in Spain, policies and interventions are needed to improve living conditions for some types of immigrant groups and an attempt should be made to achieve these three objectives: increase economic opportunities by expanding employment, increase the human capital through better education and health, and consolidate social capital and community development through the participation of immigrants. In addition, active labour market policies should be accompanied by antidiscrimination measures and integration polices that consider the heterogeneity of immigrants. This heterogeneity is related to characteristics such as age, educational background, ethnicity, and language and can be seen as an important factor that places immigrants at different starting points in the labour market. In conclusion, policy intervention should be more flexible and allow for individual adjustments. 


\section{References}

Adserà, A., Chiswick, B. R. (2007), “Are there gender and country of origin differences in immigrant labor market outcomes across European destinations?”, Journal of Population Economics, 20 (3), pp. 495526.

Amuedo-Dorantes C, de la Rica S. (2011), “Complements or substitutes? Task specialization by gender and nativity in Spain”, Labour Economics, forthcoming.

Antón, J.-I., Muñoz de Bustillo, R., Carrera, M. (2010a), "From guests to hosts: immigrant-native wage differentials in Spain", International Journal of Manpower, 31 (6), 645-659.

Antón, J.-I., Muñoz de Bustillo, R., Carrera, M. (2010b), Raining stones? Female immigrants in the Spanish Labor Market, MPRA Paper 20582.

Barsky, R., Bound, J. Charles, K. Lupton, J. (2002). "Accounting for the Black-White Wealth Gap: A Nonparametric Approach”, Journal of the American Statistical Association, 97, pp. 663-673.

Beach, C. M., Worswick, C. (1993), “Is there a double negative effect on the earnings of immigrant women?", Canadian Public Policy - Analyse de Politiques, XIX (1), pp. 36-53.

Becker, G. S. (1964), Human capital: A theoretical and empirical analysis with special reference to education, Chicago, University of Chicago Press.

Blinder, A. S. (1973), "Wage Discrimination: Reduced Form and Structural Estimates”, Journal of Human Resources 8 (4), pp. 436-455.

Buchinsky, M. (1994), “Changes in the U.S. Wage Structure 1963-1987: Application of Quantile Regression”, Econometrica. 62, pp. 405-458.

Card, D. (2005), “Is the new immigration really so bad?”, Economic Journal, 115, pp. F300-F323.

Chiswick B. (1978), “The Effect of Americanization on the Earnings of Foreign-born Men”, Journal of Political Economy, 86 (5), pp. 897-921.

DiNardo, J., Fortin, N. M., Lemieux, T. (1996), "Labor Market Institutions and the Distribution of Wages, $1973-$ 1992: A Semiparametric Approach”, Econometrica, 64 (5), pp. 1001-1044.

Donald, S., Green, D., Paarsh, H. (2000). "Differences in Wage Distributions between Canada and the United States: An Application of a Flexible Estimator of Distribution Functions in the Presence of Covariates." Review of Economic Studies, 67, pp. 609-633.

Fortin, N., Lemieux, T., Firpo, S. (2011), "Decomposition Methods in Economics" in Ashenfelter, O. and Card, D. (eds.) Handbook of Labour Economics 4 A, pp. 1-102.

García Perez, J.I. (2007), “La Muestra Continua de Vidas Laborales (MCVL): una guía de uso para el análisis de transiciones”. Revista de Economía Aplicada, XVI, p. 5-28.

Hayfron, J. E. (2002), "Panel estimates of the earnings gap in Norway: do female immigrants experience a double earnings penalty?", Applied Economics, 34 (11), pp. 1441-1452.

Izquierdo, M., Lacuesta, A., Vegas, R. (2009), “Assimilation of Immigrants in Spain: A Longitudinal Analysis”, Labour Economics, 16, pp. 669-678.

Juhn, C.. Murphy, K., Pierce, B. (1993), "Wage inequality and the rise in returns to skill”, Journal of Political Economy, 101 (31), pp. 410-442. 
Le, A., Miller, P. (2010), "Glass ceiling and double disadvantage effects: women in the US labour market", Applied Economics, 42 (5), pp. 603-613.

Long, J. E. (1980), “The Effect on Americanization on Earnings: Some Evidence for Women”, Journal of Political Economy, 88, pp. 620-629.

Mincer, J. (1974), Schooling, experience and earnings, Columbia University Press, New York.

Neuman, S., Oaxaca, R. (2004), "Wage decomposition with selectivity corrected wage equations: A methodological note", Journal of Economic Inequality, 2, pp. 3-10.

Nicodemo C. (2010), Heterogeneity across Immigrants in the Spanish Labour Market: Advantage and Disadvantage, UAB Working Paper.

Nielsen, H. S., Rosholm, M., Smith, N. (2000), Hit Twice? Danish Evidence on the Double-Negative Effect on the Wages of Immigrant Women, CEPR DP 2502.

Ñopo, H. (2008), "Matching as a Tool to Decompose Wage Gaps", The Review of Economics and Statistics, 90 (2), pp. 290-299.

Oaxaca, R. L. (1973), "Male-Female Wage Differentials in Urban Labor Markets", International Economic Review 14 (3), pp. 673-709.

OECD (2011), International Migration Outlook 2011, Paris.

Rebhun, U. (2008), “A Double Disadvantage? Immigration, Gender, and Employment Status in Israel”, European Journal of Population/Revue européenne de Démographie, 24 (1), pp. 87-113.

Rebhun, U. (2009), "Immigration, Gender, and Earnings in Israel", European Journal of Population/Revue européenne de Démographie, 26 (1), pp. 73-97.

Rendall, M. S., Tsang, F., Rubin, J. K., Rabinovich, L., Janta, B. (2010), “Contrasting Trajectories of LaborMarket Integration Between Migrant Women in Western and Southern Europe", European Journal ofPopulation/Revue européenne de Démographie, 26 (4), pp. 383-410.

Rubin, J., Rendall, M. S., Rabinovich, L., Tsang, F, van Oranje-Nassau, C., Janta, B. (2008), Migrant women in the European labour force. Current situation and future prospects, RAND Technical report.

Shamsuddin, A. F. M. (1998), "The double-negative effect on the earnings of foreign-born females in Canada", Applied Economics, 30, 1187-1201.

Simón, H., Ramos, R., Sanromá, E. (2008), "La evolución de las diferencias salariales por razón de sexo en España (1995-2002)”, Revista de Economía Aplicada, 48 (XVI), pp. 37-68.

Simón, H., Sanromá, E., Ramos, R, (2008), "Labour segregation and immigrant and native-born wage distributions in Spain: an analysis using matched employer-employee data", Spanish Economic Review, $10(2)$, pp. 135-168.

Stanley, T. D., Barrell, S. B. (1998), “Gender wage discrimination bias? A meta-regression analysis", Journal of Human Resources, 33 (4), pp. 947-973.

Wagner, J. (2007), "What a difference a Y makes. Female and Male Nascent Entrepeneurs in Germany”,Small Business Economics, 28 (1), pp. 1-21.

Weichselbaumer, D., Winter-Ebmer, R. (2005), "A Meta-Analysis of the International Gender Wage Gap", Journal of Economic Surveys, 19 (3), pp. 479-511. 


\section{Endnotes}

[1] See, for instance, Wagner (2007).

[2] See Card (2005) for a survey.

[3] Stanley and Barrell (1998) and Weichselbaumer and Winter-Ebmer (2005) have shown, using metaanalytic techniques, that these differences are robust to the consideration of different data sets, methodologies, countries and time periods.

[4] Other studies, such as Rehbuhn (2008) or Rendall et al. (2010), have focused on the analysis of double discrimination of immigrant women in employment probabilities, an issue that we will not consider here. Although Rebuhn (1998) found evidence of a positive discrimination for some groups of particular immigrant women using data for Israel, Rendall et al. (2010) analysed nine European countries and found different results according to the origin country and years of residence.

[5] Neuman and Oaxaca (2004) suggest a different procedure to take into account the problem of selectivity when analysing gender wage differences. However, as discussed in the survey by Fortin et al. (2011), the "philosophy" behind the need to control for common support is different: If migrants are concentrated in a set of occupations that are different from those of natives, the difference in wages between the two groups should consider the fact that many occupations are carried out only by members of one group. Thus, considering those differences explicitly could be important for understanding the differences between the two groups. This is different from the issue of selectivity, in which some observable characteristics can determine a previous decision of whether to participate in the labour market.

[6] We consider Germany, Italy, Portugal, the UK, the rest of EU 15, the US and Canada as "developed countries". We have excluded "France" from the analysis because, in the MCVL, immigrants from Guadalupe, Reunion, Polynesia, and Mayetta are also included in this category, although the characteristics of their origin region are very different. The remainder of the countries shown in table 1 are included in the "developing countries" category.

[7] In sets 2, 3 and 4, schooling has been replaced by occupation because the information about education in the MCVL is not updated regularly but rather is related to the educational level at the moment of the first labour contract. For this reason, and as suggested by García-Pérez (2007), in this database, the occupation could be a better proxy of qualification than the schooling level for some individuals. It is worth mentioning two further limitations of our data set. First, it does not provide information on years since migration. However, according to Population Registers, more than $80 \%$ of total immigrants came to Spain recently, specifically between 2000 and 2007, so most of them are in a similar position regarding the time of residence in Spain. Second, and again related to the education variable, it is not possible to distinguish between education in Spain and abroad. However, if we look at the percentage of immigrant women who finished studies in Spain according to the 2007 National Immigrant Survey (Encuesta Nacional de Immigrantes), they represent only 5\% of immigrants (the figure is even lower for immigrants from developing countries).

[8] A similar result was found by Nicodemo (2010). 


\section{Tables and figures}

Table 1. Descriptive statistics of the analysed sample in 2008

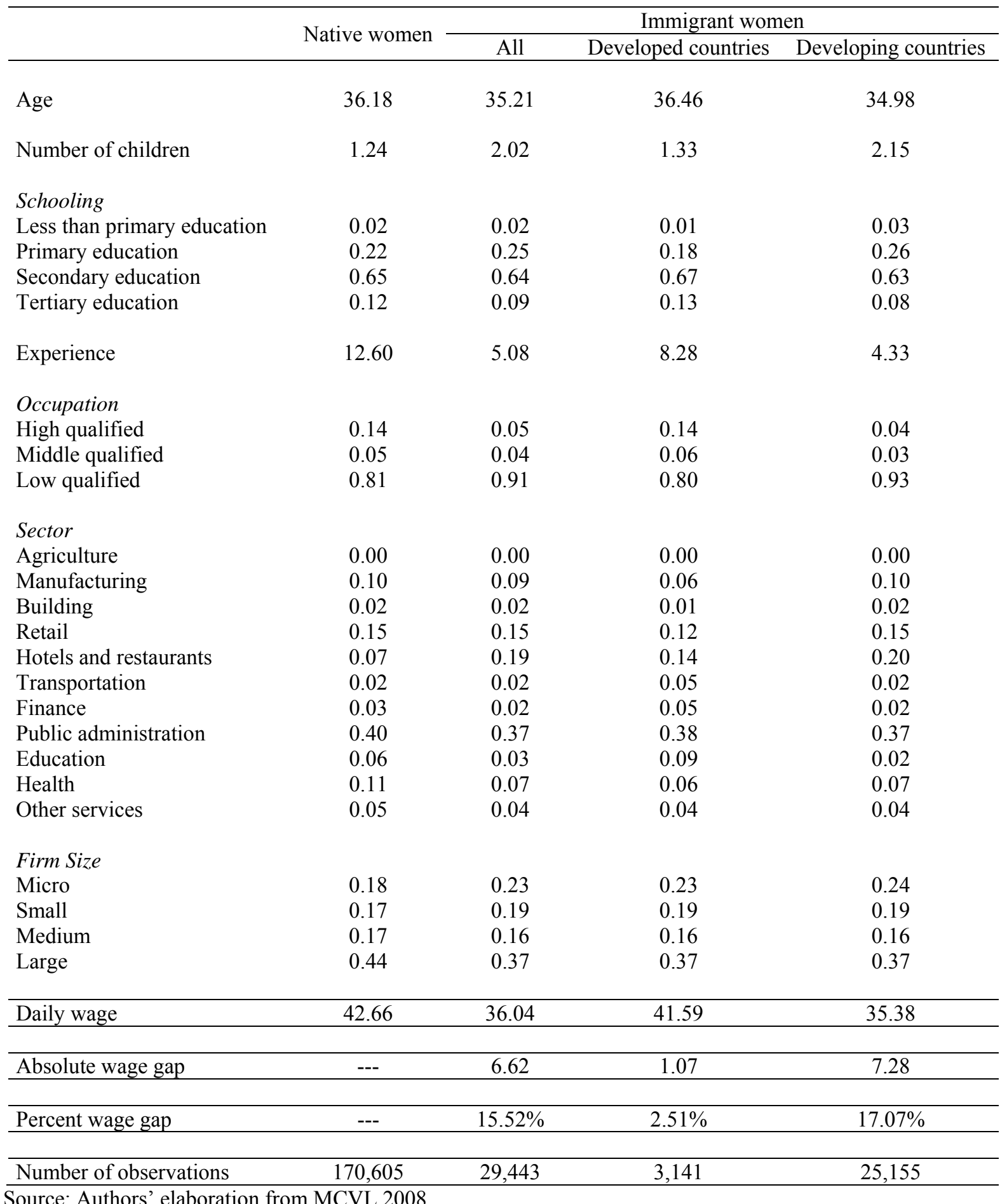




\section{Table 2. Unexplained wage gap and non-overlapping support}

\begin{tabular}{|c|c|c|c|c|c|}
\hline & $\Delta 0$ & $\begin{array}{c}\% \text { Immigrants Unmatched } \\
\text { Total } \\
\text { Immigrants }\end{array}$ & $\%$ Natives Unmatched & $\begin{array}{c}\Delta 0 \\
\text { Developing } \\
\text { countries } \\
\end{array}$ & $\begin{array}{c}\Delta 0 \\
\text { Developed } \\
\text { countries } \\
\end{array}$ \\
\hline Age, schooling & 3.13 & $0 \%$ & $0 \%$ & 3.52 & 1.36 \\
\hline Age, occupation & 2.10 & $0 \%$ & $0 \%$ & 2.34 & 1.32 \\
\hline Age, occupation, number of children & 1.29 & $1 \%$ & $1 \%$ & 1.29 & 1.24 \\
\hline Age, occupation, number of children, experience & -1.60 & $2 \%$ & $3 \%$ & -1.50 & -0.61 \\
\hline Age, education, occupation, number of children, experience, sector, firm size & -1.46 & $30 \%$ & $50 \%$ & -1.64 & -1.18 \\
\hline
\end{tabular}

Source: Authors' elaboration from MCVL 2008. 
Figure 1. Kernel density of log of the daily wage for natives and immigrants (men and women)

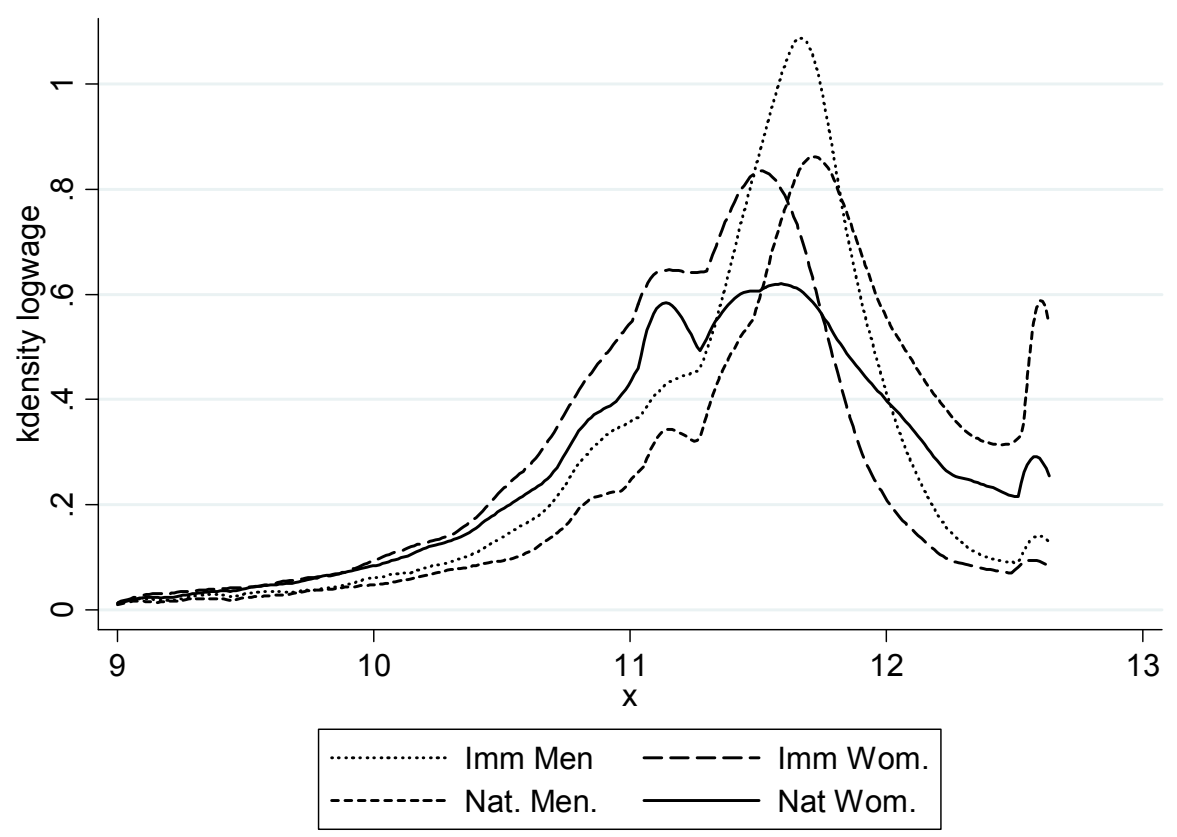

Source: Authors' elaboration from MCVL 2008. Log of the daily wage for men and women between 17 and 64 years of age.

Figure 2. Kernel density of log of the daily wage for immigrant women and native women

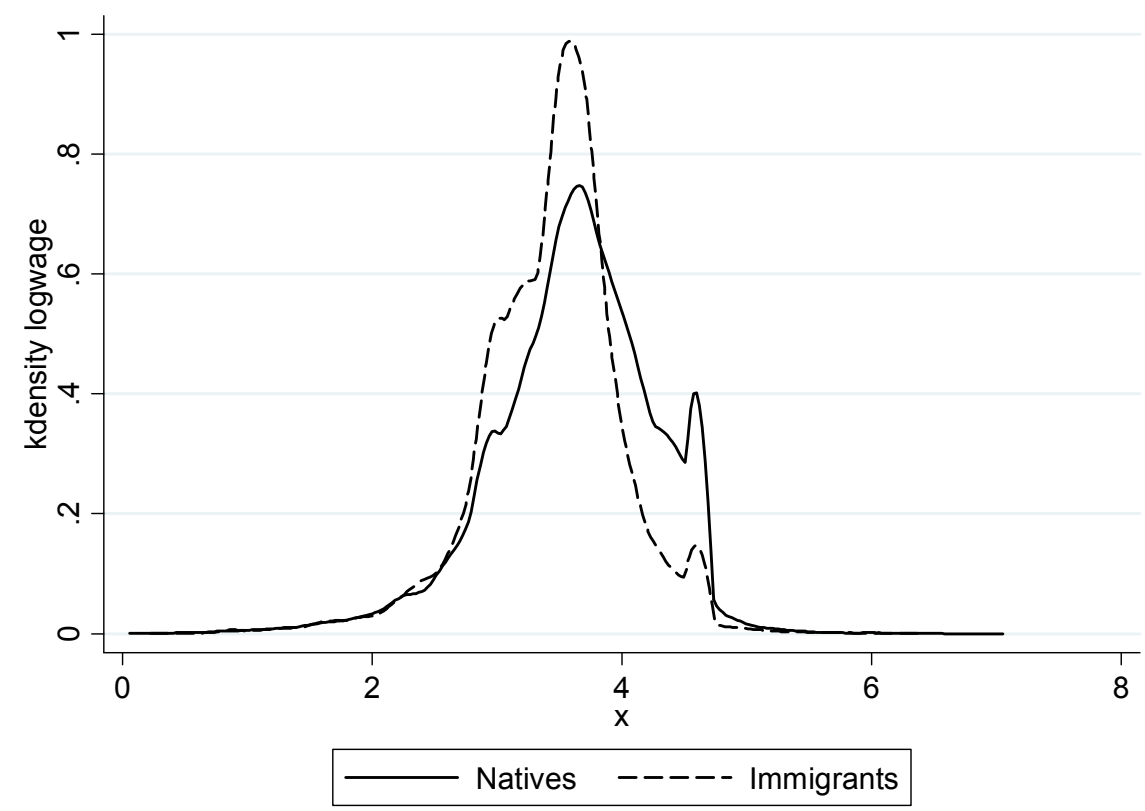

Source: Authors' elaboration from MCVL 2008. Log of the daily wage for women between 17 and 64 years of age. 
Figure 3. Kernel density of log of the daily wage of immigrant women from developed countries and native women

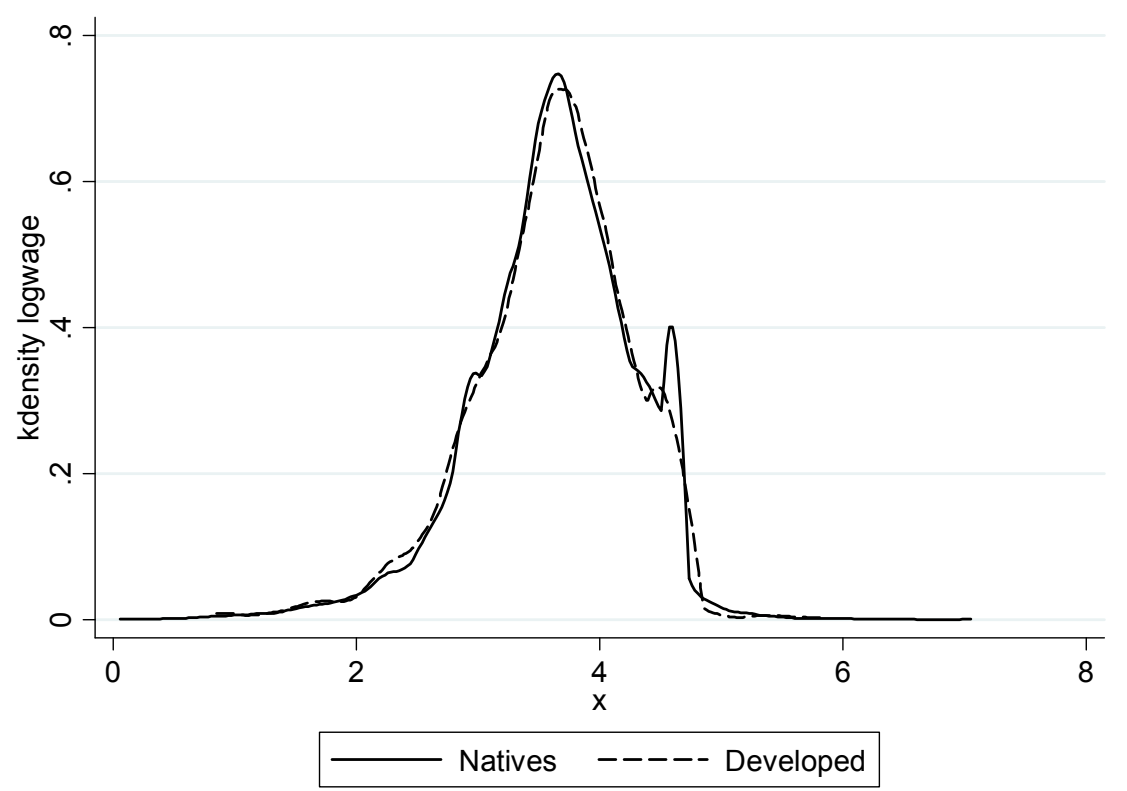

Source: Authors' elaboration from MCVL 2008. Log of the daily wage for women between 17 and 64 years of age.

Figure 4. Kernel density of log of the daily wage of immigrant women from developing countries and native women

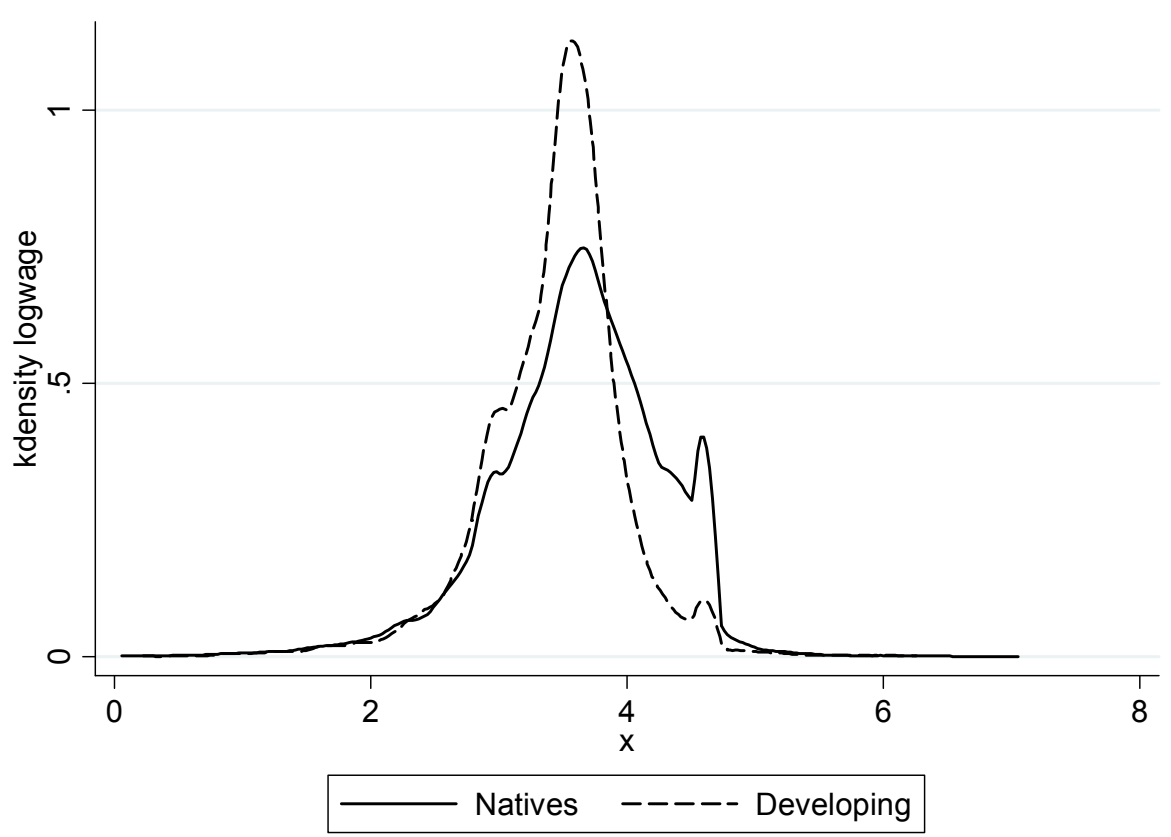

Source: Authors' elaboration from MCVL 2008. Log of the daily wage for women between 17 and 64 years of age. 
Figure 5. Wage gap decomposition for different sets of controls in 2008:

Immigrant women vs. Native women

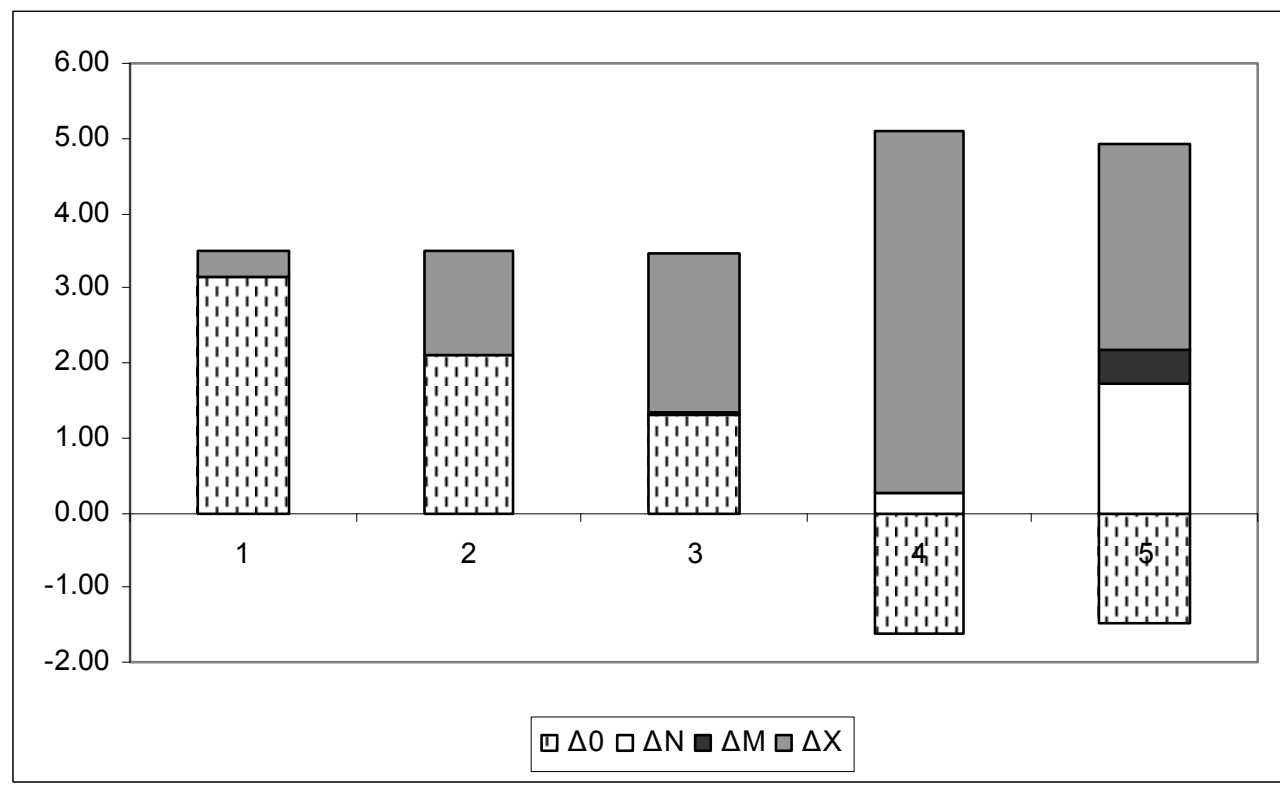

Set 1: Age, Schooling; Set 2: Age, occupation; Set 3: Age, occupation, number of children; Set 4: Age, occupation, number of children, experience; Set 5: Age, schooling, number of children, experience, sector, occupation, firm size.

Source: Authors' elaboration from MCVL 2008.

Figure 6. Wage gap decomposition for different sets of controls in 2008:

\section{Immigrant women from developed countries vs. Native women}

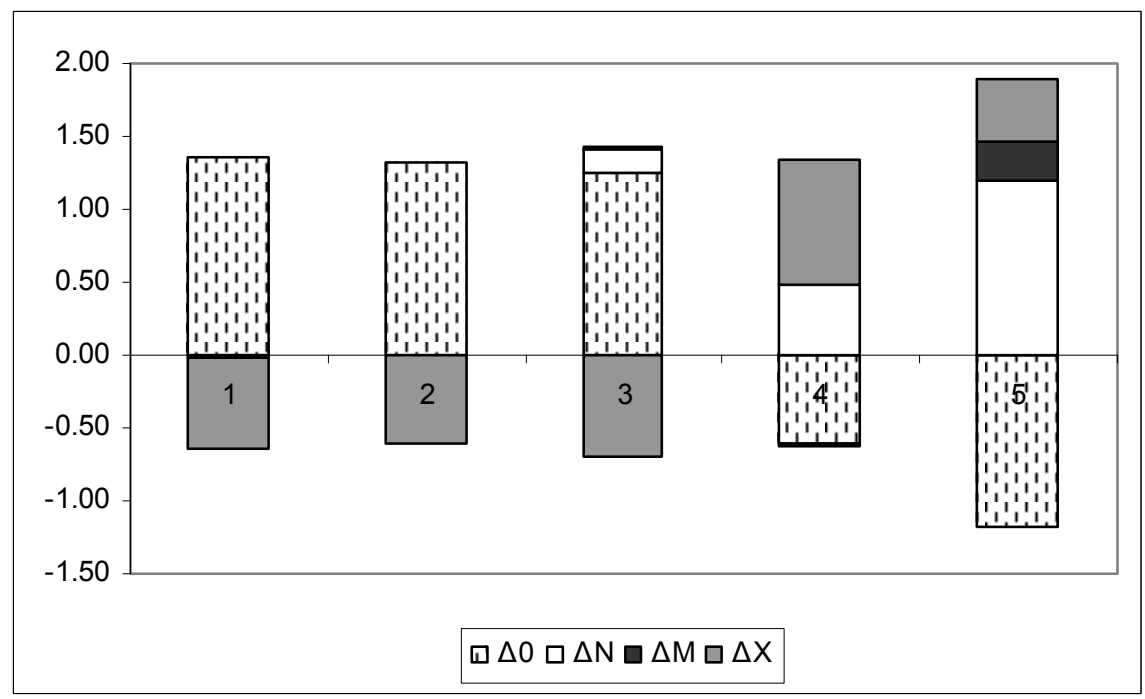

Set 1: Age, schooling; Set 2: Age, occupation; Set 3: Age, occupation, number of children; Set 4: Age, occupation, number of children, experience; Set 5: Age, schooling, number of children, experience, sector, occupation, firm size.

Source: Authors' elaboration from MCVL 2008. 
Figure 7. Wage gap decomposition for different sets of controls in 2008:

Immigrant women from developing countries vs. Native women

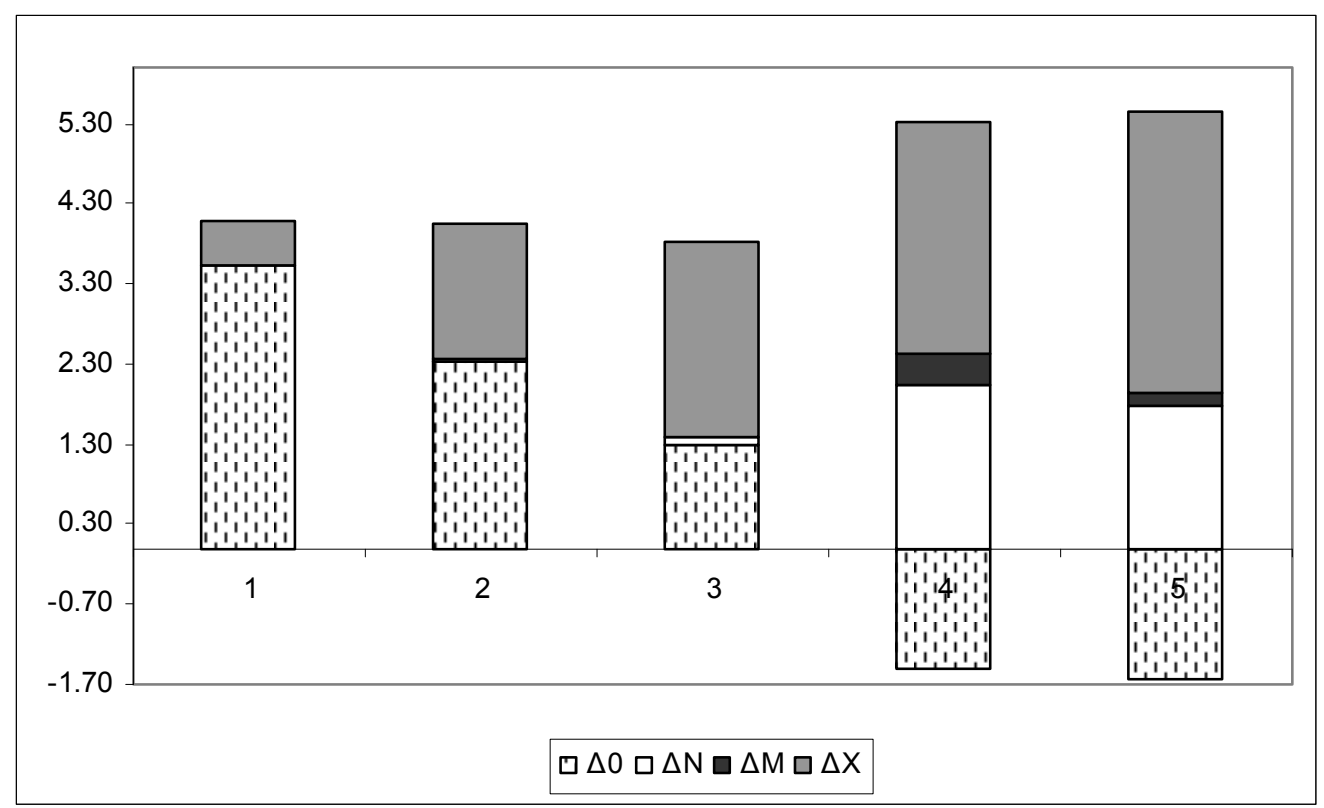

Set 1: Age, schooling; Set 2: Age, occupation; Set 3: Age, occupation, number of children; Set 4: Age, occupation, number of children, experience; Set 5: Age, schooling, number of children, experience, sector, occupation, firm size.

Source: Authors' elaboration from MCVL 2008.

Figure 8. Relative and absolute unexplained wage gap by quantiles after matching in 2008: Immigrant women vs. Native women
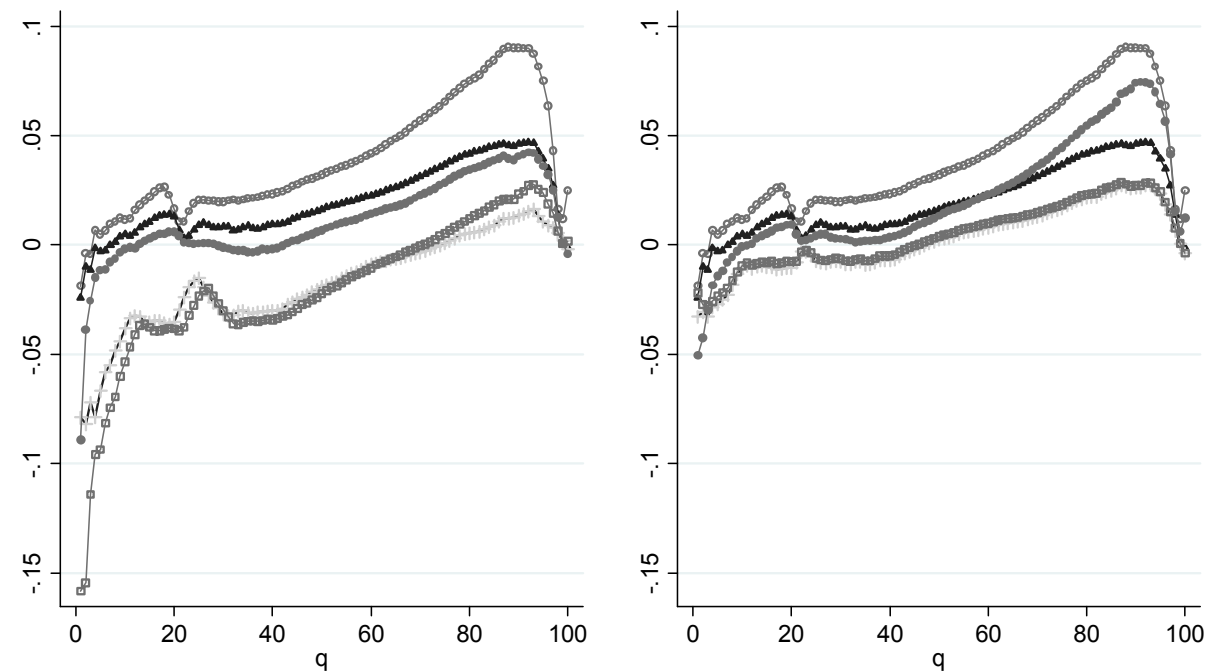

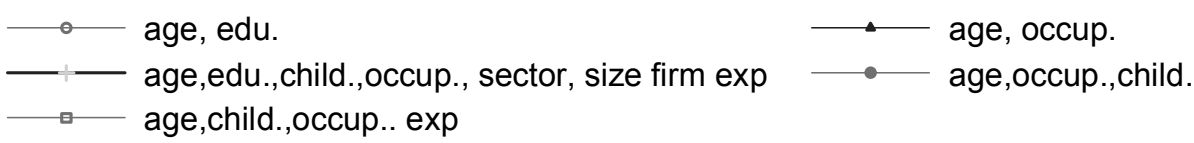

Source: Authors' elaboration from MCVL 2008. 
Figure 9. Relative and absolute unexplained wage gap by quantiles after matching in 2008: Immigrant women from developed countries vs. Native women
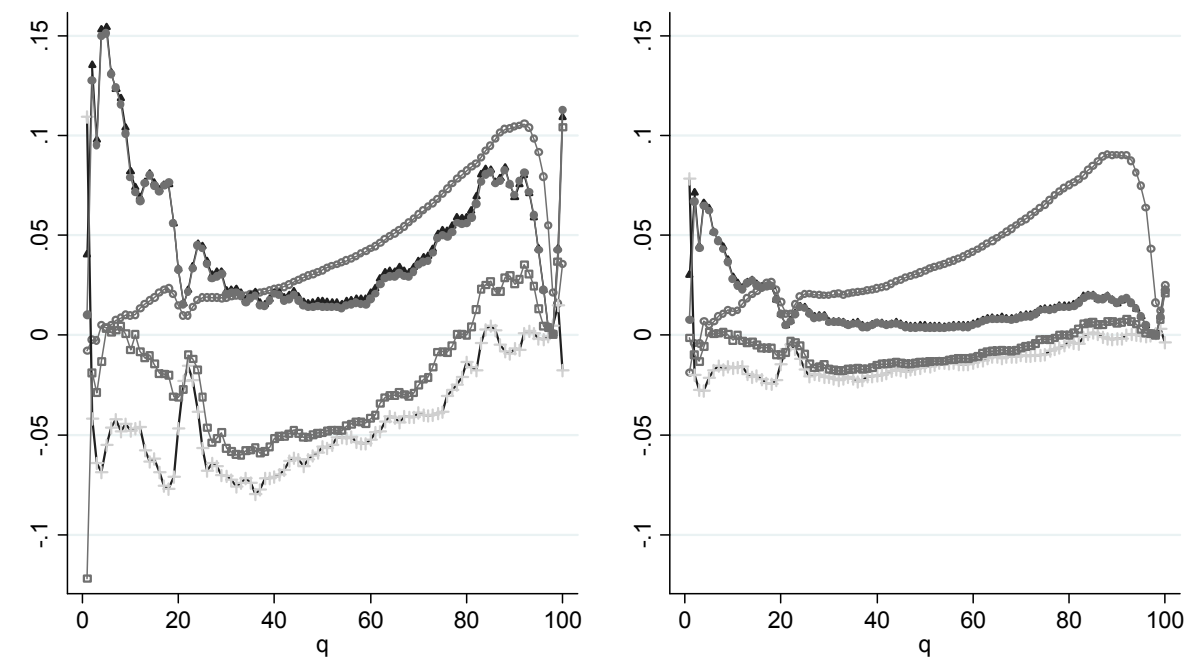

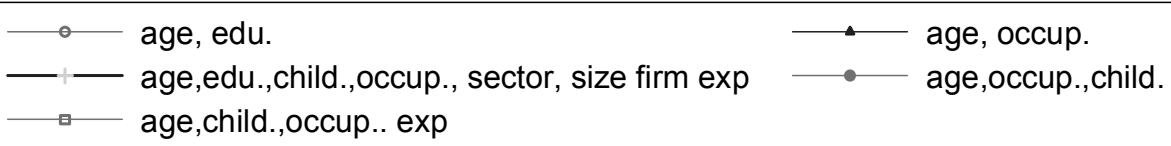

Source: Authors' elaboration from MCVL 2008.

Figure 10. Relative and absolute unexplained wage gap by quantiles after matching in 2008: Immigrant women from developing countries vs. Native women
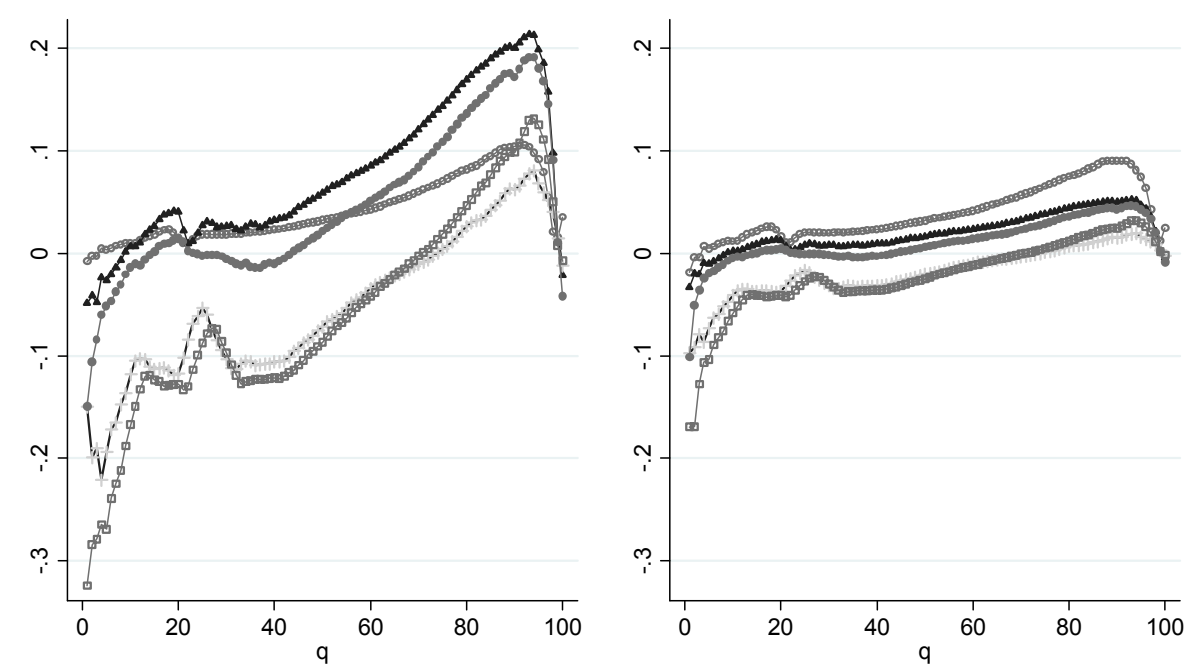

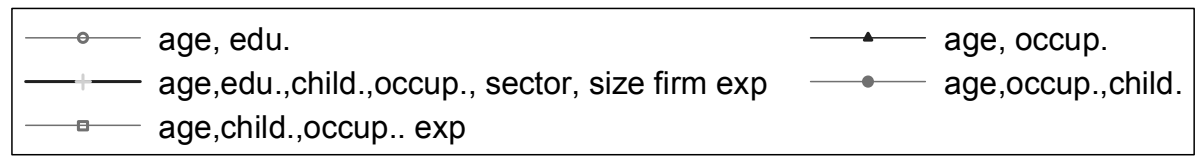

Source: Authors' elaboration from MCVL 2008. 